\title{
OS FÃS DA SELEÇÃO BRASILEIRA DE RUGBY E AS SUAS CONE- XÕES COM A SELEÇÃO E COM A MODALIDADE
}

\author{
Ivan Furegato Moraes \\ Doutor, Escola de Educação Física e Esporte da Universidade de São Paulo - EEFE/USP, São Paulo (Brasil) \\ ifuregato@gmail.com \\ Luis Henrique Torquato Vanucci \\ Mestre, Escola de Educação Física e Esporte da Universidade de São Paulo - EEFE/USP, São Paulo (Brasil) \\ luis_vanucci@gmail.com \\ iD Ary José Rocco Junior \\ Doutor, Escola de Educação Física e Esporte da Universidade de São Paulo - EEFE/USP, São Paulo (Brasil) \\ aryrocco@usp.br
}

Objetivo: Identificar e classificar como os fãs da seleção brasileira de rugby se conectam com a seleção e com a modalidade.

Metodologia: A pesquisa se caracteriza como aplicada, descritiva, quantitativa e realizada através do método Survey. O questionário foi aplicado antes do jogo da seleção brasileira de rugby com a amostra definida por conveniência e de forma não probabilística. Os dados obtidos foram analisados com base na Estatística Descritiva e na Análise Fatorial Exploratória.

Originalidade/relevância: A pesquisa evidencia, de forma inédita, o comportamento do consumidor/torcedor da seleção brasileira de rugby, identificando os fatores que o conectam com a equipe e com a modalidade, gerando sugestões para o desenvolvimento do rugby no país.

Principais resultados: Entre os 117 respondentes 54\% eram homens com uma idade média de 31,90 anos. 62\% eram solteiros, $31 \%$ pós-graduados e $64 \%$ não residiam na cidade de São Paulo. Os oito fatores gerados explicaram $67,32 \%$ da variância identificada, sendo, em parte, diferentes dos conectores indicados na teoria utilizada. O torcedor respondente possuía um significativo engajamento com a modalidade e com a seleção, sendo influenciado pela figura do ídolo e pela família, mas com um limitado consumo de produtos e presença nos jogos.

Contribuições teóricas/metodológicas: O estudo inicia as pesquisas sobre o comportamento do consumidor de rugby no Brasil e inova ao aplicar a teoria base utilizada ao contento brasileiro e no rugby, revelando pontos a serem adaptados e abordados em estudos futuros.

Palavras-chave: Comportamento do consumidor. Rugby. Consumidor esportivo. Confederação Brasileira de Rugby.

\section{Cite como}

American Psychological Association (APA)

Moraes, I. F., Vanucci, L. H. T., \& Rocco Junior, A. J. (2020). Os fãs da seleção brasileira de rugby e as suas conexões com a seleção e com a modalidade. PODIUM Sport, Leisure and Tourism Review, São Paulo, 9(2), 171-176.

https://doi.org/10.5585/podium.v9i2.15253.

\footnotetext{
Agradecimentos

O presente trabalho foi realizado com apoio da Coordenação de Aperfeiçoamento de Pessoal de Nível Superior - Brasil (CAPES) - Código de Financiamento 001, a quem os autores agradecem. Agradecimento também aos revisores pelas importantes considerações realizadas para o aperfeiçoamento do artigo.
} 


\section{FANS OF THE BRAZILIAN RUGBY NATIONAL TEAM AND THEIR CONNECTIONS WITH THE NATIONAL TEAM AND THE MODAL- ITY}

Objective: To identify and classify how fans of the Brazilian rugby National team connect with the National team and the modality.

Methodology: The research is characterized as applied, descriptive, quantitative and performed through the Survey method. The questionnaire was applied before the game of the Brazilian rugby National team with the sample defined by convenience and in a non-probabilistic way. The data obtained were analyzed based on descriptive statistics and exploratory factor analysis.

Originality/Relevance: The research shows, in an unprecedented way, the behavior of the consumer/fan of the Brazilian rugby National team, identifying the factors that connect it with the team and the modality, generating suggestions for the development of rugby in the country.

Main results: Among the 117 respondents $54 \%$ were men with a mean age of 31.90 years. $62 \%$ were single, $31 \%$ were post-graduates and $64 \%$ did not reside in the city of São Paulo. The eight factors generated explained $67.32 \%$ of the identified variance and were partly different from the connectors indicated in the theory used. The respondent fan had a significant engagement with the modality and National team, being influenced by the figure of the idol and the family, but with a limited consumption of products and presence in the games.

Theoretical/methodological contributions: The study initiates research on the behavior of the rugby consumer in Brazil and innovates by applying the base theory used to the Brazilian and rugby context, revealing points to be adapted and addressed in studies Future.

Keywords: Consumer behavior. Rugby. Sports consumer. Brazilian Rugby Confederation.

\section{FANS DEL EQUIPO NACIONAL DE RUGBY DE BRASIL Y SUS CO- NEXIONES CON EL EQUIPO Y LA MODALIDAD}

Objetivo: Identificar y clasificar cómo los aficionados del equipo brasileño de rugby se conectan con la selección y la modalidad.

Metodología: La investigación se caracteriza como aplicada, descriptiva, cuantitativa y realizada a través del método de Survey. El cuestionario se aplicó antes del partido del equipo brasileño de rugby con la muestra definida por conveniencia y de manera no probabilística. Los datos obtenidos se analizaron sobre la base de estadísticas descriptivas y análisis de factores exploratorios.

Originalidad/Relevancia: La investigación muestra, sin precedentes, el comportamiento del consumidor/incha del equipo brasileño de rugby, identificando los factores que lo conectan con el equipo y la modalidad, generando sugerencias para el desarrollo del rugby en el país.

Principales resultados: Entre los 117 encuestados, el 54\% eran hombres con una edad media de 31,90 años. El 62\% eran solteros, el $31 \%$ eran postgraduados y el $64 \%$ no residían en la ciudad de Sao Paulo. Los ocho factores generados explicaron el $67,32 \%$ de la varianza identificada, y fueron en parte dife- 
rentes de los conectores indicados en la teoría utilizada. El incha encuestado tuvo un compromiso significativo con la modalidad y el equipo nacional, siendo influenciado por la figura del ídolo y la familia, pero con un consumo limitado de productos y presencia en los juegos.

Contribuciones teóricas/metodológicas: El estudio inicia la investigación sobre el comportamiento del consumidor de rugby en Brasil e innova al aplicar la teoría básica utilizada en el contexto brasileño y del rugby, revelando puntos a adaptar y abordar en estudios Futuro.

Palabras clave: Comportamiento del consumidor. Rugby. Consumidor deportivo. Confederación Brasileña de Rugby.

\section{Introdução}

Em um cenário no qual a Indústria do Esporte está cada vez mais globalizada e oferecendo variadas opções para os consumidores/torcedores, questões que afetam diretamente o esporte brasileiro, conhecer os consumidores esportivos e compreender o seu comportamento de consumo a fim de criar ou melhorar o relacionamento do consumidor/torcedor com a organização esportiva tem se tornado um fator crítico para o sucesso das diferentes organizações esportivas (Rocco Junior, 2019).

Entender detalhadamente o comportamento do consumidor do esporte é, hoje, imprescindível para o gestor do esporte que pretenda atuar em um mercado cada vez mais competitivo. O desenvolvimento tecnológico e as ferramentas de comunicação digital encontraram no universo esportivo e nas experiências que somente o esporte pode proporcionar um excelente conteúdo para envolver e fidelizar o consumidor esportivo. Conhecer quem é este indivíduo interessado em consumir o esporte como conteúdo, entretenimento e/ou experiência, alicerces da Indústria do Esporte, torna-se necessidade fundamental para todos aqueles que pretendem trabalhar, estudar ou pesquisar o esporte no cenário global atual (Rocco Junior, 2019).

Um dos principais vetores dos estudos relacionados ao comportamento do consumidor é o entendimento das razões e motivações pelas quais os consumidores adquirem determinados produtos e/ou serviços em detrimento a outros similares e concorrentes. Assim, os gestores do esporte buscam aumentar o comprometimento dos torcedores e, consequentemente, o consumo e as receitas das organizações esportivas. Por outro lado, os torcedores/consumidores enfrentam um dilema devido ao crescente número de produtos esportivos, com o comprometimento a determinadas modalidades afetado por diferentes fatores, como os financeiros, geográficos e valores pessoais (Rein, Kotler \& Shields, 2008).

Nesse contexto, pesquisas sobre o comportamento do consumidor destacam-se como uma das principais áreas dentro do Marketing Esportivo, seja no ambiente acadêmico ou prático. Segundo Stewart, Smith e Nicholson (2003), o desejo de entender o padrão de consumo do consumidor esportivo tem sido um objetivo perseguido há muito tempo pelos profissionais de marketing, sendo que, para Lopes e Silva (2011), desde a década de 1950 teorias tem sido desenvolvidas por pesquisadores de marketing para descrever, compreender e prever o comportamento dos consumidores.

Em paralelo, o rugby se destaca como uma das principais modalidades esportivas mundiais, fato comprovado pelos números da última edição da Copa do Mundo de Rugby, realizada em 2019 no Japão. A competição teve 99,3\% dos ingressos vendidos, uma audiência televisiva global de 857 milhões de pessoas e atraiu para o país sede mais de 400 mil turistas, com ações 
anteriores ao campeonato gerando, somente na Ásia, 2,27 milhões de novos praticantes (Rugby World Cup Japan 2019, 2020b, 2020c).

A competição também obteve grande alcance online, com um aumento de 1,8 milhões de seguidores nas redes sociais oficiais, 2,1 bilhões de visualizações dos vídeos oficiais e o aplicativo oficial teve mais de 1,2 milhões de downloads (Rugby World Cup Japan 2019, 2020a). Tais números reforçam a afirmação de Silva, Mezzadri, Souza e Souza (2015) de que a popularidade global do rugby foi um dos principais fatores que a fizeram retornar ao programa olímpico, fato ocorrido nos Jogos Olímpicos do Rio de Janeiro, em 2016.

Já no Brasil, é possível observar o crescimento do rugby a partir da criação da Confederação Brasileira de Rugby (CBRu) em 2010. A entidade, ao adotar uma gestão profissional, conseguiu elevar o número de praticantes e torcedores, atraindo novos consumidores principalmente com o desenvolvimento de competições nacionais e da seleção brasileira (Fávero, 2018).

Portanto, diante da necessidade de compreensão do consumidor esportivo para melhorar a relação deste consumidor com a entidade esportiva e do crescimento do rugby no Brasil, representado em muito pelo crescimento esportivo e de torcedores da seleção brasileira, buscouse neste presente estudo identificar e classificar as formas como os fãs da seleção brasileira de rugby se conectam com a seleção e com a modalidade.

\section{Revisão de literatura}

\subsection{Motivações do consumidor esportivo}

Um dos primeiros passos para identificar o perfil dos torcedores esportivos passa por entender não apenas o que esse fã (neste estudo denominado como "Torcedor/Consumidor" TC) representa, mas, como é que ele se conecta a uma modalidade esportiva (Rein et al., 2008), pois os espectadores constituem a chave para o sucesso das organizações esportivas (Dhurup, 2010).

Segundo Alonso e O'Shea (2014), inúmeras pesquisas têm sido realizadas para analisar os atributos comportamentais e psicológicos dos consumidores do esporte profissional com o interesse, particularmente, de compreender os atributos e os motivos dos TCs e dos entusiastas do esporte ao se relacionarem com os times e as ligas profissionais.

Nesse sentido, diversos instrumentos foram desenvolvidos por diferentes autores, como escalas para mensurar variáveis e fatores ligados ao consumo do esporte. Entre os autores que propuseram esses instrumentos, Trail e James (2001) desenvolveram a Motivation Scale for Sport Consumption (MSSC - Escala de Motivação para Consumo Esportivo), que envolve nove motivos: realização, aquisição de conhecimento, estética, drama, fuga, família, atração física, habilidade física e interação social.

Funk e James (2001) desenvolveram o modelo Psycological Continuum Model (PCM Modelo de Continuidade Psicológica), cujo objetivo é analisar o envolvimento do fã e do espectador do esporte considerando quatro níveis: consciência, atração, pertencimento e fidelidade.

Para Gladden e Funk (2002), as ligações dos TCs com as equipes podem ser construídas a partir de três tipos de conexões específicas. O primeiro tipo acontece por meio dos recursos e produtos relacionados, por exemplo, ao treinador, ao logotipo da organização, aos ídolos, as cores da equipe, as instalações e outros serviços. A segunda conexão ocorre por meio de alguns benefícios proporcionados pelas experiências devido ao relacionamento ou através de alguma ligação simbólica (sócio torcedor, posição social, auto identificação) do consumidor com a organização. Por último, os autores citam a conexão dos consumidores por meio de atitudes. 
Já Ross, James e Vargas (2006) desenvolveram uma escala com o intuito de medir a associação da marca do time no esporte profissional: a Team Brand Association Scale (TBSA - Escala de Associação de Marca de Equipe), formada por onze dimensões que abordam a personalidade "não-jogador"; o sucesso do time; a história do time; a comunidade do estádio; as características do jogo do time; a marca; o compromisso; os atributos organizacionais; as concessões; a interação social; e a rivalidade.

Especificamente sobre os torcedores de rugby, Garland, Macpherson e Haughey (2004) realizaram pesquisa com TCs da Nova Zelândia para verificar os fatores que influenciavam o comparecimento nos jogos. A partir dos fatores indicados por Tomlinson, Buttle e Moores (1995), os pesquisadores identificaram que a disputa esportiva, a atmosfera do ambiente dos jogos e aspectos das instalações esportivas foram os principais motivadores dos torcedores.

Entre os inúmeros instrumentos existentes para analisar o envolvimento dos TCs optamos por utilizar como base teórica para a pesquisa a teoria dos conectores dos fãs com o esporte, desenvolvida por Rein et al., (2008). Os autores indicam pontos de relacionamento (conexões/conectores) dos TCs com as modalidades esportivas que revelam os motivos que fazem com que as pessoas optem por determinados produtos ou modalidades esportivas, com as conexões formando três grupos:

- Conectores fundamentais: formado por duas conexões, o Astro e o Local, consideradas como fundamentais para a ligação com o esporte. O primeiro aborda o lado humano dos esportes, com o qual o TC consegue se relacionar e expressar diferentes emoções. Quanto ao Local, é onde o esporte está enraizado e relacionado com a identificação e o engajamento com a comunidade;

- Conectores de comunicação social: composto por dois conectores, a Moeda Social e a Família, que, segundo Rein et al. (2008), se tornaram fundamentais na atual era da informação, já que potencializam o poder de união dos esportes, gerando interligação entre os TCs através da interação social e emocional promovido pelos eventos esportivos;

- Conectores de busca: constituído por três conexões, a Experiência Indireta, a Incerteza e a Utopia, que:

[...] proporcionam aos torcedores a satisfação de uma necessidade fundamental, um processo ao longo do qual muitas vezes constroem seu próprio mundo esportivo. $\mathrm{O}$ valor desses conectores para a indústria do esporte passou a aumentar constantemente com a tendência de muitos torcedores de buscar níveis mais elevados de experimentação de emoções e com a interação maior do torcedor com os esportes, maior do que em qualquer época, permitida pelos avanços da arquitetura, tecnologia e das teorias dos esportes. (Rein et al., 2008, p.74)

Dentro destes três grandes grupos estão subdivididos os seguintes pontos de conexões (Rein et al., 2008):

a) Astro: alguém ou algo que tem potencial de atração para conectar o fã. No primeiro caso, esse "alguém", pode conectar um fã ao esporte por meio de suas ações, personalidade ou capacidade técnica. Logo, compete às organizações esportivas a manutenção das personalidades no elenco e, além disso, ampliar o número de "astros" e utilizá-los como instrumento de atração, aproximando-os dos fãs;

b) Local: capitalizam a presença de equipes, atletas e instalações e predispõem os torcedores a apoiar esportes que sejam da sua área ou que representem a sua comunidade. Nesse conector 
percebe-se diretamente a ligação e filiação ao local de origem, ao ponto de residência, seja atual ou não. Nesses casos, muitas vezes, as escolas conseguem manter o vínculo dos seus ex-alunos com a instituição, apoiando o esporte da escola;

c) Moeda social: esporte como elemento de ligação entre grupos de amigos, comunidades e outras relações, cuja informação compartilhada mantém e incentiva a relação social. Esse ambiente incentiva os relacionamentos dos fãs, independentemente do jogo em si, pois, muitas vezes, esse compartilhamento de informações acontece em um momento do lanche ou durante uma aula qualquer, por exemplo;

d) Família: nesse conector o esporte atua como fator de união, ajudando a manter as tradições e os valores familiares, estabelecendo, inclusive, conexões com parentes afastados. O conector família cria novos torcedores, principalmente pelo fato do esporte ser apresentado por um membro da família;

e) Experiência Indireta: o vínculo com o esporte acontece através da identificação, admiração ou imitação das habilidades e desempenho de atletas ou mesmo de uma equipe. No caso deste conector, o combustível para manter esta relação, é o desejo do fã de ter cada vez mais acesso ao esporte e aos atletas de determinada modalidade, o que tem se intensificado com a desenvolvimento das tecnologias que aproximam ainda mais o fã das realidades do esporte;

f) Incerteza: o que conecta os fãs e os mantém interessados no esporte, neste caso, é a imprevisibilidade, a espontaneidade e tentativa de prever resultados, o que proporcionam, inclusive, um escape à monotonia do dia-a-dia;

g) Utopia: nesta conexão a atração dos fãs acontece por experiências que representam o passado e recordações que recriam determinados esportes, por exemplo. Esses torcedores que se conectam ao esporte pelo conector "utopia" não aceitam os altos salários dos atletas profissionais, as alterações das regras e tão pouco a introdução de novas tecnologias para praticar velhos esportes. Ao contrário de tudo isso, eles gostariam de ver as equipes mais simples, focadas apenas na competição.

Rein et al. (2008) também descrevem para cada um dos sete conectores identificados os benefícios, riscos e implicações gerencias para as organizações esportivas que os adotarem (Quadro 1). 
Moraes, I. F., Vanucci, L. H. T., \& Rocco Junior, A. J. (2020). Os fãs da seleção brasileira de Rugby e as suas conexões com a seleção e com a modalidade Quadro 1 - Conectores dos TCs com o esporte

\begin{tabular}{|c|c|c|c|}
\hline Conector & Benefícios & Riscos & Implicações \\
\hline Astro & Grande força de TCs e poder de venda de produtos diversos & $\begin{array}{l}\text { Conexões voláteis, temporárias e de difícil } \\
\text { gestão }\end{array}$ & $\begin{array}{c}\text { Criação de novos astros e criação de interações entre } \\
\text { eles e os TCs }\end{array}$ \\
\hline Local & $\begin{array}{l}\text { Permite a clara definição do mercado, o qual possui um } \\
\text { elevado engajamento }\end{array}$ & $\begin{array}{l}\text { Os TCs podem ser manipulados e há o risco } \\
\text { de perda de atratividade }\end{array}$ & $\begin{array}{l}\text { Necessidade de aproximação das instituições locais } \\
\text { para a criação de marca e imagem fortes e adequadas }\end{array}$ \\
\hline Moeda Social & Informações esportivas são facilmente divulgadas & $\begin{array}{l}\text { Surgimento de torcedores mais interessados } \\
\text { em interações sociais do que no } \\
\text { esporte em si }\end{array}$ & $\begin{array}{l}\text { Necessidade do desenvolvimento de eventos que gerem } \\
\text { uma experiencia social completa e ampla divulgação } \\
\text { das informações }\end{array}$ \\
\hline Família & $\begin{array}{l}\text { Aprofunda a ligação com o produto esportivo e cria } \\
\text { experiencias memoráveis e duradouras, além de permitir a } \\
\text { interação entre gerações }\end{array}$ & $\begin{array}{l}\text { Comportamento antiético e negativo das } \\
\text { organizações esportivas e experiencias nega- } \\
\text { tivas podem afastar toda a família }\end{array}$ & $\begin{array}{l}\text { Inserir no eventos atividades para toda a família e usar } \\
\text { as instalações esportivas de forma mais adequada }\end{array}$ \\
\hline $\begin{array}{l}\text { Experiência } \\
\text { Indireta }\end{array}$ & $\begin{array}{l}\text { Torcedor relacionado a esse conector é mais engajado e } \\
\text { disposto a consumir }\end{array}$ & $\begin{array}{l}\text { Não atender as expectativas e não possuir as } \\
\text { inovações desejadas pelo torcedor }\end{array}$ & $\begin{array}{l}\text { Uso das novas tecnologias para aumentar e manter a } \\
\text { conexão e engajamento do torcedor }\end{array}$ \\
\hline Incerteza & $\begin{array}{l}\text { Aumenta a aceitação da imprevisibilidade e do drama esportivo, } \\
\text { além de gerar comprometimento financeiro e emocional }\end{array}$ & $\begin{array}{c}\text { Pode diminuir a fidelidade com uma } \\
\text { modalidade, pois a busca pelo imprevisível } \\
\text { é superior. }\end{array}$ & $\begin{array}{l}\text { Necessidade de definir limites éticos, principalmente os } \\
\text { relacionados ao mercado de apostas }\end{array}$ \\
\hline Utopias & $\begin{array}{l}\text { Torcedores nostálgicos são facilmente identificáveis e consumi- } \\
\text { dores frequentes de produtos ou ações que relembrem o passado }\end{array}$ & $\begin{array}{l}\text { Mudanças no esporte podem os afastar } \\
\text { e há a tendência de busca por esportes } \\
\text { menos comerciais }\end{array}$ & $\begin{array}{c}\text { Esses torcedores precisam ser considerados quando } \\
\text { ocorrem mudanças e a tecnologia pode ser utilizada } \\
\text { para valorizar o passado, atraindo-os }\end{array}$ \\
\hline
\end{tabular}

Fonte: adaptado de Rein et al., (2008). 
Apesar das conexões serem os pontos de contatos que ligam os TCs ao esporte, as origens e razões das mesmas podem ser diferentes (Rein et al., 2008). Portanto, a compreensão do comportamento dos fãs, por exemplo, permite a realização de estratégicas de marketing direcionadas para incentivar a participação deles nos jogos (Dhurup, 2010). Nesse sentido, Dhurup (2010) afirma que estudos sobre a frequência dos fãs de esporte nos jogos têm sido realizados extensivamente em países como Estados Unidos e Austrália, bem como na Europa.

\subsection{Rugby no Brasil}

A origem do rugby brasileiro remota ao final do século XIX quando a modalidade foi introduzida no país por marinheiros e imigrantes ingleses, principalmente na cidade do Rio de Janeiro (Melo, 2013). A difusão do rugby foi acelerada, principalmente em São Paulo, por Charles Miller que, em 1894, ao retornar de um período de estudos na Inglaterra, trouxe livros de regras e bolas tanto de futebol como de rugby (Cafeo, 2013; Melo, 2013). Andrade (2019) aponta que Miller, em 1895, fundou a primeira equipe de São Paulo, o São Paulo Athletic Club. Contudo, como o foco de Miller era o desenvolvimento do futebol, a equipe foi descontinuada logo após a sua criação (Andrade, 2019; Gutierrez, 2016).

A prática regular do rugby se consolidou somente a partir da década de 1920, sendo realizada por equipes formadas em clubes socioesportivos paulistas e cariocas, a maioria de membros das elites locais, com frequentes jogos e torneios interestaduais (Andrade, 2019; Cafeo, 2013; Melo, 2013). Na década de 1930 ocorreram amistosos internacionais contra seleções de países em que a modalidade já estava consolidada, como Reino Unido e África do Sul (Cafeo, 2013). Contudo, o desenvolvimento da modalidade no Brasil foi interrompido pelo início da II Guerra Mundial (Andrade, 2019; Gutierrez, 2016).

A partir da década de 1950 teve início um lento processo de reestruturação do rugby brasileiro (Andrade, 2019), com destaque para o surgimento da primeira instituição voltada à organização e direção da modalidade, a União de Rúgbi do Brasil (URB), fundada em seis de outubro de 1963, em São Paulo (Andrade, 2019; Silva et al., 2015). Nesse período, o rugby começa a se expandir, principalmente entre universitários, com a primeira partida universitária sendo realizada em 1966 (Cafeo, 2013; Gutierrez, 2016).

A URB, visando ser reconhecida pelo então Conselho Nacional de Desportos como entidade máxima do rugby brasileiro, foi substituída pela Associação Brasileira de Rugby (ABR) em 1972 (Cafeo, 2013; Silva et al., 2015). Em paralelo, durante a década de 1970, a modalidade foi inserida em escolas particulares tradicionais da cidade de São Paulo, aumentado o número de praticantes (Andrade, 2019).

Segundo Gutierrez, Antonio, Kater e Almeida (2017), no final da década de 1980 a prática da modalidade ainda era restrita no país, com a ABR tendo o registro de 19 equipes de somente três estados: São Paulo, Rio de Janeiro e Paraná. A partir da década de 1990 o processo de popularização da modalidade ganhou força incentivado pelo início das transmissões de jogos internacionais em canais de televisão pagos (Gutierrez, 2016).

O resultado dessa expansão foi a participação, em 1996 e pela primeira vez, da seleção masculina nas eliminatórias para a Copa do Mundo de Rugby de 1999 (Silva et al., 2015). Apesar de não obter a vaga na competição, a participação chamou a atenção da Internacional Rugby Board, entidade que controlava a modalidade mundialmente, que vislumbrou o Brasil como um possível polo de desenvolvimento do rugby, levando a um estreitamento das relações com a ABR e gerando investimento no desenvolvimento da modalidade 
Moraes, I. F., Vanucci, L. H. T., \& Rocco Junior, A. J. (2020). Os fãs da seleção brasileira de Rugby e as suas conexões com a seleção e com a modalidade

(Andrade, 2019; Silva et al., 2015).

Cafeo (2013), a partir de dados da ABR, indica que entre 2004 e 2009 houve um crescimento do rugby no Brasil, com aumento de 40 para 230 equipes registradas, essas localizadas em 22 estados. O número de praticantes federados cresceu de cinco para 30 mil e dez estados organizavam campeonatos, apesar da modalidade apresentar problemas financeiros, principalmente devido à falta de patrocinadores.

Apesar da situação financeira, as perspectivas para o rugby brasileiro eram positivas em 2009 devido ao citado crescimento, pela reentrada da modalidade no programa olímpico e pela criação do Grupo de Apoio ao Rugby Brasileiro (GRAB), formado por empresários praticantes da modalidade que visavam estimular o seu desenvolvimento (Cafeo, 2013; Silva et al., 2015).

Nesse contexto e objetivando modernizar a estrutura da ABR e obter apoio do então Ministério do Esporte e do Comitê Olímpico Brasileiro foi criada, em 2010, a Confederação Brasileira de Rugby (CBRu). A entidade passou a ser a responsável pela gestão do rugby brasileiro, especialmente pelo alto rendimento, pela realização de competições e pelo desenvolvimento e disseminação da modalidade, além de representá-la junto as entidades internacionais e aos órgãos governamentais (Andrade, 2019; Cafeo, 2013; Silva et al., 2015).

Para alavancar o desenvolvimento do rugby, a diretoria da CBRu adotou uma gestão profissional por meio de normas, diretrizes, princípios de governança e compliance e diferentes estratégias, principalmente com a criação e implementação do plano intitulado "Projeto 2016", além de buscar atrair patrocinadores e obter recursos governamentais (Cafeo, 2013; Melo, 2013).

As mudanças gerenciais logo surtiram efeito e ainda em 2010 a entidade obteve seu primeiro patrocínio, da empresa de material esportivo Topper, além da primeira transmissão ao vivo pela televisão de jogos da seleção, em 2011. Destaque também para a captação de recursos federais por meio de legislações e programas, como "Lei de Incentivo ao Esporte", "Lei Agnelo-Piva" e "Projeto Rio 2016" (Silva et al., 2015). Os recursos governamentais, juntamente com os patrocinadores, possibilitaram a consolidação da CBRU e a execução do planejamento realizado.

O sucesso da gestão implementada na CBRu pode ser observado por diversos aspectos, como os resultados divulgados pela entidade (Brasil Rugby, 2019a), o fato dela ser considerada, desde 2014, uma das confederações mais bem geridas do Brasil (Brasil Rugby, 2019 b) e, principalmente, pelo crescimento da modalidade, havendo atualmente mais de 60 mil praticantes, 11 mil jogadores federados, 133 atletas de alto rendimento, 300 clubes distribuídos em todos os estados e seis federações estaduais (Brasil Rugby, 2019a; Brasil Rugby, s.d.). Além disso, entre os anos de 2015 a 2017, o número de pessoas que se interessaram pelo rugby no país cresceu significativamente, saindo de 23,7 para 30,3 milhões de pessoas, o que representa um crescimento anual de 13\%, (Brasil Rugby, 2018).

Esse crescimento possibilitou a modalidade obter espaço na mídia, especialmente em canais televisivos esportivos por assinatura e em sites temáticos, contribuindo para a transformação do rugby brasileiro em um espetáculo de consumo (Gutierrez et al., 2017). Contudo, ainda não é possível afirmar que o rugby é um esporte popular no Brasil, fato comprovado pelos dados dos jogos da seleção brasileira de rugby realizados na cidade de São Paulo, nos estádios do Pacaembu e no Allianz Parque, em 2016, onde, respectivamente, 67\% e 52\% dos torcedores que compareceram nunca tinham acompanhado presencialmente uma partida de rugby (Brasil Rugby, 2016).

Diante do desafio de popularizar ainda mais a modalidade a CBRu consolidou alguns torneios nacionais, como o Super 16, campeonato brasileiro da primeira divisão masculina, 
que em 2018 foi disputado por 16 times; a Taça Tupi, correspondente ao campeonato brasileiro da segunda divisão masculina; e o Super Sevens, o campeonato brasileiro feminino (Brasil Rugby, 2018).

A entidade também atuou para fortalecer as seleções masculinas e femininas, que participam de competições do calendário internacional. A partir deste foco outros eventos foram organizados pela CBRu com o objetivo de atrair um número maior de torcedores/consumidores (Brasil Rugby, 2019a). Entre eles destaque para o jogo amistoso entre a seleção brasileira masculina e a neozelandesa (Maori All Blacks), realizado em novembro de 2018 no estádio do Morumbi, em São Paulo.

A partida, até então o maior evento organizado pela $\mathrm{CBRu}$, contou com um público total de 34.541 pessoas, recorde da modalidade no país, foi transmitida ao vivo por um canal esportivo pago, com uma audiência superior a 1 milhão de pessoas e gerou repercussão mundial devido tanto ao elevado público em um pais sem tradição na modalidade como pelo desempenho além do esperado da seleção brasileira, indicando também um desenvolvimento técnico da modalidade no Brasil (Brasil Rugby, 2019a; Senechal, 2018).

A expectativa da CBRu com o jogo amistoso era que o torcedor brasileiro que estivesse conhecendo a modalidade tivesse uma experiência positiva, desenvolvendo uma conexão com ela e, também com a equipe que a representa, neste caso, a seleção brasileira. Nesse contexto esportivo e diante da limitada quantidade de estudos acadêmicos no Brasil que apontam as motivações que levam os torcedores a consumirem o esporte, especialmente o rugby e a seleção brasileira da modalidade, realizou-se a presente pesquisa.

\section{Métodos}

Para que os objetivos fossem alcançados foi realizada uma pesquisa aplicada visando gerar conhecimentos de aplicação prática (Silva \& Menezes, 2005). Além disso, a pesquisa caracteriza-se como descritiva e de abordagem quantitativa, que, de acordo com Silva e Menezes (2005), trata-se de um tipo de estudo onde as informações obtidas são quantificadas, traduzindo em números as opiniões e informações para posterior classificação e análise. Por fim, a pesquisa foi realizada por meio do método Survey (Freitas, Oliveira, Saccol \& Moscarola, 2000; Gil, 2002; Veal \& Darcy, 2014), que pode ser descrito como a obtenção de características, ações ou opiniões de determinado grupo, indicado como representante de uma população-alvo, por meio de um instrumento de pesquisa, normalmente o questionário (Freitas et al., 2000).

O instrumento utilizado para a coleta de dados foi um questionário elaborado com base nos conectores que unem os fãs ao esporte indicados por Rein et al. (2008). O questionário foi composto por 30 afirmações/variáveis elaboradas pelos pesquisadores a partir dos sete conectores indicados no referencial teórico adotado (Quadro 2), que foram julgadas pelos respondentes por meio de uma escala de quatro níveis: (1) discordo totalmente; (2) discordo; (3) concordo; (4) concordo totalmente (Malhotra, 2012). Também foram incluídas no questionário oito questões sobre o perfil sociodemográfico dos respondentes: gênero, idade, filhos, estado civil, escolaridade, renda familiar, local de residência e se a pessoa praticava rugby. 
Quadro 2 - Afirmações/variáveis de cada conector

Conector

Astro

Local

Moeda Social

Família

Experiência Indireta

Incerteza

Utopia
1) Vou ao estádio para ver o meu ídolo da seleção brasileira de rugby jogar.

2) Eu compro "itens colecionáveis" (camisas, souvenir, etc.) do meu ídolo.

3) Acompanho meu ídolo da seleção brasileira de rugby nas redes sociais.

4) Mantenho contato pessoal com um ídolo da seleção brasileira de rugby.

5) Vou ao estádio pela proximidade com minha casa.

6) Gosto de participar de eventos esportivos (qualquer modalidade) que acontecem nos estádios.

7) Sempre assisto aos jogos da seleção brasileira de rugby no estádio.

8) Tenho acesso aos locais restritos para imprensa, vestiários, etc.

9) Assisto aos jogos de qualquer equipe de rugby pela TV.

10) Participo de torcida organizada da seleção brasileira de rugby.

11) Contribuo com doações, incentivos fiscais, dinheiro, materiais, etc., para a seleção brasileira de rugby.

12) Sempre participo de atividades ligadas a um fã-clube da seleção brasileira de rugby.

13) Participo de grupos de redes sociais relacionados à seleção brasileira de rugby.

14) Costumo assistir os jogos da seleção brasileira de rugby com meus amigos.

15) Reúno meus familiares para assistir aos jogos da seleção brasileira de rugby.

16) Sempre acompanho os jogos da seleção brasileira de rugby nos canais de mídia.

17) Deixo de comparecer a programas familiares para assistir ao jogo da seleção brasileira de rugby no estádio.

18) Minha família influencia, de alguma forma, para que eu acompanhe a seleção brasileira de rugby.

19) Sempre compro produtos da seleção brasileira de rugby para presentear meus familiares.

20) Acompanho o rugby, pois minha família me incentiva a buscar novas experiências esportivas.

21) Sou sócio de algum clube de rugby.

22) Sempre opino em canais de comunicação da seleção brasileira de rugby.

23) Pagaria para obter os melhores lugares (assentos) dentro do estádio.

24) Compro materiais esportivos da seleção, como camisetas, bolas, chaveiros, etc.

25) Participo de apostas (bolões) ligadas ao rugby.

26) Sempre torci para a seleção brasileira de rugby.

27) Sempre gostei das mesmas modalidades esportivas.

28) Participarei de eventos que envolvam ex-atletas de rugby, sempre que convidado.

29) Sempre opto por modalidades esportivas menos populares.

30) Acompanho a modalidade, pois me identifico com os valores do rugby.

O questionário foi aplicado junto aos torcedores que acompanharam in loco a partida amistosa entre a seleção brasileira masculina de rugby e seleção neozelandesa (Maori All Blacks), realizada no dia 10 de novembro de 2018 no Estádio do Morumbi, São Paulo. A 
amostra foi definida por conveniência e de forma não probabilística (Hair, Black, Babin \& Anderson, 2014).

A coleta ocorreu por meio da aplicação da versão imprensa do questionário durante a entrada dos torcedores, no lado externo do estádio, sendo que os participantes responderam o questionário de forma autônoma, sem a participação dos pesquisadores, com a recolha dos dados afetada devido a razões climáticas.

A análise dos dados obtidos foi realizada de duas maneiras: os dados sociodemográficos foram analisados com base na Estatística Descritiva, com uso das frequências das respostas e do desvio padrão (Farias \& Laurencel, 2006). Já os dados sobre as variáveis foram analisados através da técnica de Análise Fatorial Exploratória (Aranha \& Zambaldi, 2008; Hair et al., 2014), procedimento estatístico no qual os dados oriundos das variáveis são reduzidos em fatores que resumem e explicam as características e/ou o comportamento de uma amostra (Malhotra, 2012), com suporte do software SPSS para Windows, versão 25.

Inicialmente, os dados foram analisados para verificar ausentes e discrepantes e na sequência foram realizados os testes de Kaiser-Meyer-Olkin (KMO), para avaliar a adequação da Análise Fatorial, sendo considerada adequada se o valor for superior a 0,5; e o Teste de Esfericidade de Bartlett, para verificar a hipótese de que as variáveis não são correlacionadas com a população, questão comprovada se o nível de significância for $\mathrm{p}<0,05$ (Hair et al., 2014; Malhotra, 2012).

Os fatores resultantes da Análise Fatorial Exploratória foram extraídos por meio da análise de componente principal e a interpretação das variáveis e dos fatores ocorreu por meio da análise da rotação VARIMAX, realizada para minimizar o número de variáveis com carga fatorial elevada em um fator e melhorar a sua interpretação, e pela carga fatorial das variáveis. Foram desconsideradas as variáveis com carga fatorial menor que 0,50 (Costello e Osborne, 2005; Hair et al., 2014; Malhotra, 2012).

Por fim, a confiabilidade da consistência interna dos fatores obtidos foi calculada e comprovada por meio do cálculo do coeficiente de Alpha de Cronbach, sendo considerado satisfatório resultados superiores a 0,60 (Hair et al., 2014).

\section{Resultados}

Ao todo 117 questionários foram respondidos. Sobre a parte sociodemográfica, parte dos participantes não responderam todas as questões, com 54\% se declarando do sexo masculino $(\mathrm{N}=109)$, a idade média identificada foi de 31,90 anos $(\mathrm{N}=96, \mathrm{DP}=11,51), 62 \%$ eram solteiros (28\% casados, $6 \%$ divorciados, $3 \%$ separados e $1 \%$ viúvos, $\mathrm{N}=106)$ e $51 \%$ dos respondentes afirmaram não possuírem filhos $(\mathrm{N}=101)$.

Com relação ao nível mais alto de escolaridade, dos 101 respondentes dois afirmaram possuírem o $1^{\circ}$ grau (2\%), 17 o Ensino Médio (17\%), 51 graduação (50\%), 15 especialização (15\%) e 16 Mestrado ou Doutorado (16\%). Sobre a renda familiar, 5\% afirmaram ser de até $\mathrm{R} \$ 1.449,00 ; 21 \%$ entre $\mathrm{R} \$ 1.450,00$ e $\mathrm{R} \$ 2.899,00 ; 36 \%$ entre $\mathrm{R} \$ 2.900,00$ e $\mathrm{R} \$ 7.249,00$; $25 \%$ entre $\mathrm{R} \$ 7.250,00$ e $\mathrm{R} \$ 14.499,00$; e $13 \%$ acima de $\mathrm{R} \$ 14.500,00(\mathrm{~N}=102)$.

Dos 109 respondentes que indicaram o local de residência 64\% afirmaram não serem da cidade de São Paulo, enquanto os moradores da capital eram principalmente da zona sul $(15 \%)$ e da zona oeste $(9 \%)$, regiões próximas ao estádio. Por fim, sobre a prática do rugby, $37 \%$ declararam jogar a mais de um ano, $7 \%$ a menos de ano, $3 \%$ pretendia começar a praticar e 53\% nunca jogaram $(\mathrm{N}=109)$. 
Antes da Análise Fatorial Exploratória, os 117 questionários foram analisados e 21 foram excluídos por terem dados ausentes ou discrepantes. O teste KMO resultou em 0,774, indicando, segundo Hair et al. (2014), um nível médio de adequação e o teste de Bartlett verificou a existência de correlações significativas $(1354,868$ e p: 0,000).

Das 30 afirmações/variáveis do questionário, 25 foram significativas, uma (5: "Vou ao estádio pela proximidade com minha casa") se mostrou inadequada e quatro $(4,22,26$ e 29) foram desconsideradas por apresentarem uma baixa carga fatorial, sendo uma relacionada ao Fator 1 (do conector Experiência Indireta), duas ao Fator 2 (dos conectores Astro e Incerteza) e uma ao Fator 8 (do conector Utopia). Ao final da análise fatorial foram identificados oito fatores que explicaram 67,32\% do total da variância (Tabela 1). 
Moraes, I. F., Vanucci, L. H. T., \& Rocco Junior, A. J. (2020). Os fãs da seleção brasileira de Rugby e as suas conexões com a seleção e com a modalidade

Tabela 1 - Resultados da Análise Fatorial Exploratória

\begin{tabular}{|c|c|c|c|c|c|c|c|c|}
\hline Afirmações/Variáveis & $\begin{array}{c}\text { Fator } 1 \text { - } \\
\text { Engajamento }\end{array}$ & $\begin{array}{c}\text { Fator } 2 \\
\text { - Ídolo }\end{array}$ & $\begin{array}{l}\text { Fator } 3- \\
\text { Moeda } \\
\text { social }\end{array}$ & $\begin{array}{l}\text { Fator } 4 \text { - } \\
\text { Família }\end{array}$ & $\begin{array}{l}\text { Fator } 5 \text { - } \\
\text { Consumo }\end{array}$ & $\begin{array}{c}\text { Fator } 6 \text { - } \\
\text { Local }\end{array}$ & $\begin{array}{c}\text { Fator } 7 \text { - } \\
\text { Agregados }\end{array}$ & $\begin{array}{c}\text { Fator 8- } \\
\text { Preferência }\end{array}$ \\
\hline $\begin{array}{l}\text { 16. Sempre acompanho os jogos da } \\
\text { seleção brasileira de rugby nos canais } \\
\text { de mídia. }\end{array}$ & 0,66 & & & & & & & \\
\hline $\begin{array}{l}\text { 21. Sou sócio de algum clube de } \\
\text { rugby. }\end{array}$ & 0,64 & & & & & & & \\
\hline $\begin{array}{l}\text { 30. Acompanho a modalidade, pois } \\
\text { me identifico com } \\
\text { seus valores. }\end{array}$ & 0,63 & & & & & & & \\
\hline $\begin{array}{l}\text { 9. Assisto aos jogos de qualquer } \\
\text { equipe de rugby pela TV. }\end{array}$ & 0,62 & & & & & & & \\
\hline $\begin{array}{c}\text { 14. Costumo assistir os jogos da sele- } \\
\text { ção brasileira de rugby com meus } \\
\text { amigos. }\end{array}$ & 0,59 & & & & & & & \\
\hline $\begin{array}{l}\text { 23. Pagaria para obter os melhores } \\
\text { lugares (assentos) dentro do estádio. }\end{array}$ & 0,59 & & & & & & & \\
\hline $\begin{array}{l}\text { 17. Deixo de comparecer a programas } \\
\text { familiares para assistir ao jogo da se- } \\
\text { leção brasileira de rugby no estádio. }\end{array}$ & 0,53 & & & & & & & \\
\hline $\begin{array}{l}\text { 1. Vou ao estádio para ver o meu } \\
\text { ídolo jogar. }\end{array}$ & & 0,81 & & & & & & \\
\hline $\begin{array}{l}\text { 3. Acompanho meu ídolo nas redes } \\
\text { sociais. }\end{array}$ & &, 080 & & & & & & \\
\hline $\begin{array}{l}\text { 2. Eu compro "itens colecionáveis" } \\
\text { (camisas, souvenir, etc.) } \\
\text { do meu ídolo. }\end{array}$ & & 0,58 & & & & & & \\
\hline $\begin{array}{l}\text { 13. Participo de grupos de redes soci- } \\
\text { ais relacionados à seleção brasileira } \\
\text { de rugby. }\end{array}$ & & 0,51 & & & & & & \\
\hline $\begin{array}{l}\text { 10. Participo de torcida organizada da } \\
\text { seleção brasileira } \\
\text { de rugby. }\end{array}$ & & & 0,82 & & & & & \\
\hline $\begin{array}{l}\text { 11. Contribuo com doações, incenti- } \\
\text { vos fiscais, incentivos financeiros, }\end{array}$ & & & 0,70 & & & & & \\
\hline
\end{tabular}


materiais, etc., para a seleção brasi-

$$
\text { leira de Rugby. }
$$

12. Sempre participo de atividades ligadas a um fã-clube da

seleção Brasileira de Rugby.

18. Minha família influencia, de alguma forma, para que eu acompanhe

a seleção brasileira de rugby.

20. Acompanho o rugby, pois minha

família me incentiva a

buscar novas experiências esportivas.

15. Reúno meus familiares para assistir aos jogos da seleção brasileira de rugby.

24. Compro materiais esportivos da seleção, como camisetas, bolas, chaveiros, etc.

19. Sempre compro produtos da seleção brasileira de rugby para presentear meus familiares.

6. Gosto de participar de eventos es-

$$
\text { portivos (qualquer }
$$

modalidade) que acontecem nos está-

$$
\text { dios. }
$$

7. Sempre assisto aos jogos da seleção brasileira de rugby

$$
\text { no estádio. }
$$

28. Participarei de eventos que envol-

vam ex-atletas de rugby, sempre que

$$
\text { convidado. }
$$

cesso aos locais restritos

para imprensa,

vestiários, etc.

25. Participo de apostas (bolões) ligadas ao rugby.

re gostei das mesmas moda-

lidades esportivas.

0,66

$$
\mathrm{KMO}=0,774
$$


Moraes, I. F., Vanucci, L. H. T., \& Rocco Junior, A. J. (2020). Os fãs da seleção brasileira de Rugby e as suas conexões com a seleção e com a modalidade

\begin{tabular}{ccccccccc} 
Eingevalue & 3,71 & 3,37 & 3,03 & 2,07 & 2,01 & 1,91 & 1,88 & 1,53 \\
explicada & 12,80 & 11,61 & 10,46 & 7,15 & 6,94 & 6,59 & 6,48 & 5,28 \\
lpha de Cronbach & 0,85 & 0,80 & 0,77 & 0,73 & 0,51 & 0,49 & 0,48 & - \\
\hline
\end{tabular}


O Fator 1 explicou 12,80\% da variância total, apresentou um Alpha de Cronbach de 0,854 e foi formado por sete variáveis de cinco conectores: duas de Moeda Social e de Experiência Indireta e uma de Astro, Incerteza e Utopia. O fator aborda o engajamento, através dos meios de comunicação ou in loco, e a conexão dos torcedores com o rugby e a seleção brasileira, revelando um elevado engajamento, nome utilizado para denominar o fator.

O Fator 2 explica 11,61\% da variância total, com um Alpha de Cronbach de 0,80. Foi formado por quatro variáveis de dois conectores (três de Astro e uma de Moeda Social) e foi intitulado de Astro por expressar a importância do ídolo na conexão entre o torcedor e a modalidade e a seleção. Já o Fator 3 foi composto por três variáveis do mesmo conector (Moeda Social) e indicou a participação dos torcedores em fãs clubes e torcidas organizadas da seleção brasileira de rugby, além da contribuição por meio de doações. Essa fator, rotulado de Moeda Social, explicou 10,46\% da variância, com um Alpha de Cronbach de 0,77.

O quarto fator demonstra a importância da família no engajamento com a modalidade e a seleção brasileira, sendo formado por três variáveis de dois conectores (duas de Família e uma de Moeda Social). Denominado de Família, o fator explicou 7,15\% da variância e apresentou um Alpha de Cronbach de 0,73. Por sua vez, o Fator 5, Consumo, explicou 6,94\% da variância total, com um Alpha de Cronbach de 0,51, sendo composto por duas variáveis de dois conectores (Experiência Indireta e Família) que expressam o consumo de produtos ligados à seleção brasileira de rugby.

O sexto fator foi formado por três variáveis de dois conectores (duas de Local e uma de Utopia) e aborda a participação in loco dos torcedores nos jogos, principalmente da seleção, e em outros eventos da modalidade. Essa fator, rotulado de Local, explicou 6,59\% da variância total, com um Alpha de Cronbach de 0,49. Já o Fator 7 explicou 6,48\% da variância total, apresentando um Alpha de Cronbach de 0,48. Composto por duas variáveis de dois conetores (Local e Incerteza), o fator, denominado Agregados, trata de pessoas que estavam presentes na partida, mas que não possuíam conexão com o rugby ou com a seleção, sendo, provavelmente, convidados das empresas patrocinadoras do evento. Por fim, o Fator 8, intitulado Preferência, explicou 5,28\% da variância total e foi formado por apenas uma variável de um conector (Incerteza), indicando a preferência dos torcedores por modalidades esportivas.

\section{Discussão}

Inicialmente abordaremos o perfil sociodemográfico dos torcedores usando como comparação o estudo de Dantas, Perrenoud, Marinho \& Vanucci (2017) que analisou duas partidas amistosas da seleção brasileira de rugby, contra Paraguai e Portugal, também realizadas na cidade de São Paulo em 2017 ${ }^{1}$. Em ambos os homens foram maioria: 54\% no jogo analisado e $69 \%$ nos outros dois jogos, com a média de idade próxima (31,9 x 29).

Sobre a escolaridade, a partida contra os Maori All Blacks apresentou um número de graduados e pós-graduados superior ( $82 \%$ x 67\%), com todos os jogos possuindo um número de torcedores com nível superior acima da média brasileira (15\%) (Agência IBGE, 2018a). Nos três jogos a maioria dos torcedores apresentaram rendas em níveis médios e elevados, sendo que mais de $70 \%$ citaram possuírem uma renda superior à média nacional (Agência IBGE, 2018b).

Enquanto no jogo analisado a maioria dos torcedores (64\%) não residia na cidade de São Paulo, nos jogos analisados por Dantas et al. (2017) a maioria era de paulistanos (73\%).

\footnotetext{
${ }^{1}$ Dantas et al. (2017) apresentam os resultados das duas partidas de forma consolida.
} 
Uma explicação para essa diferença pode ser o adversário e a importância e divulgação dada pela CBRu para a partida, visto que o jogo analisado foi contra uma equipe de renome internacional e com grande divulgação prévia, o que contribuiu para a atração de pessoas de fora da cidade de São Paulo.

Por fim, a maior parte dos torcedores da partida contra os Maori All Black (53\%) e das duas partidas (56\%) analisadas por Dantas et al. (2017) afirmaram que nunca praticaram rugby, ponto que se explorado pela CBRu pode trazer para a modalidade novos praticantes e torcedores.

Com relação aos fatores identificados, quatro apresentaram relação direta com os conectores indicados por Rein et al. (2008): Fator 2 (Astro), Fator 3 (Moedas Social), Fator 4 (Família) e Fator 6 (Local), sendo eles formados basicamente por afirmações/variáveis desses conectores e indicando que, em parte, eles estavam presentes e foram relevantes para a ligação dos participantes da pesquisa com o rugby e a seleção brasileira.

Por outro lado, a análise fatorial gerou quatro fatores sem ligação com os conectores iniciais: Fator 1 (Engajamento), Fator 5 (Consumo), Fator 7 (Agregados) e Fator 8 (Preferência). Os três primeiros foram formados por afirmações/variáveis oriundas de diferentes conectores, enquanto o Fator 8 foi baseado em apenas uma variável do conector Incerteza, mas sem refletir diretamente o mesmo.

Destaque também para o fato de que as variáveis relativas aos conectores Experiencia Indireta e Utopia se dispersaram entre diferentes fatores. Uma explicação para tal, a partir de Rein et al. (2008), pode ser o fato do desenvolvimento do rugby no Brasil ser recente, pois ambos fatores indicam uma ligação histórica e duradoura entre os torcedores e a modalidade. Outro ponto relevante é que o fator mais significativo (Engajamento) foi formando pelo maior número de afirmações/variáveis (sete) e pela maior quantidade de conectores (cinco), sendo o mesmo não previsto nos conectores iniciais utilizados como referência.

Com os resultados e as observações citadas é possível identificarmos discrepâncias entre os conectores indicados por Rein et al. (2008) e os fatores que ligam os torcedores respondentes ao rugby e a seleção brasileira da modalidade, o que pode ser explicado por alguns pontos como lacunas na teoria base utilizada, que foi desenvolvida em um período e contexto diferentes do qual ela foi aplicada na presente pesquisa, e por características peculiares dos entrevistados.

Outro ponto a ser discutido é que somente quatro dos oito fatores (Engajamento, Astro, Moeda Social e Família) apresentaram um valor de Alpha de Cronbach satisfatório (acima de 0,60), ou seja, possuem nível de confiabilidade dentro do indicado por Hair et al. (2006). A baixa confiabilidade dos fatores Consumo, Local, Agregado e Preferência pode ser justificada, segundo Hora, Monteiro e Arica (2010), pela sua inadequação, pelo baixo número de respondentes ou por problemas com a teoria base, principalmente com a divisão do questionário e a sua validação.

Assim, devido ao limitado número de respondentes, gerado pelos problemas climáticos ocorridos durante a coleta dos dados, e aos problemas identificados na teoria base, especialmente o agrupamento das afirmações/variáveis nos conectores, foi optado por considerar, nos resultados, os quatro fatores que obtiveram um Alpha de Cronbach abaixo do indicado por Hair et al. (2006).

Ao compararmos os fatores identificados na pesquisa com os três principais motivos indicados por Garland et al. (2004) é constatado que apenas um deles, a atmosfera do ambiente do jogo, possui relação com um dos fatores identificados, mais especificamente com o fator 6 (Local), que leva em consideração o ambiente do estádio. Os outros dois fatores indicados por Garland et al. (2004) (disputa e instalações esportivas) não se mostraram relevantes como conectores para a amostra analisada. 
Já se consideramos os fatores de motivação indicados pelos outros pesquisadores da temática é possível verificarmos que dos nove fatores considerados na MSSC (Trail \& James, 2001) apenas família, habilidade física e interação social se relacionam com os fatores identificados, respectivamente com Família, Ídolo e Moeda Social. Dos quatro itens da PCM (Funk \& James, 2001), dois se relacionam com os resultados da pesquisa: pertencimento, ligado ao fator Moeda Social, e fidelidade, relativo ao fator Engajamento. Dos três tipos de conexões indicados por Gladden e Funk (2002) apenas a que ocorre por meio dos recursos e produtos relacionados as organizações esportivas teve ligação com os resultados, por meio do fator Consumo. Por fim, das 11 dimensões abordados por Ross et al. (2006) apenas duas apresentaram ligações com os resultados: concessões, ligada ao fator Agregados, e interação social, relacionada a Moeda Social.

Assim, é possível verificar que os torcedores que foram a partida de rugby analisada apresentaram fatores de conexão com a modalidade e com a seleção brasileira em grande parte diferentes dos motivos citados pelos autores analisados, questão que pode ser justificada pela diferença temporal entre as pesquisas e por características própria da amostra e da modalidade no Brasil, visto que ela ainda é recente no país, atraindo principalmente os atuais fãs, que possuem forte engajamento com a modalidade e com os seus ídolos, mas que não levam em consideração os aspectos competitivos e as instalações esportivas utilizadas, como revelado por Garland et al. (2004).

\section{Conclusões e recomendações}

A partir dos resultados obtidos é possível concluir que os participantes da pesquisa foram, a maioria, homens, de meia idade, solteiros e sem filhos. Os mesmos apresentaram uma elevada escolaridade e renda, não residindo na cidade de São Paulo e não praticando o rugby.

Também foi identificado que o torcedor respondente possuía um significativo engajamento com a modalidade e com a seleção brasileira, sendo influenciado pela figura do ídolo e pela sua família, mas com um limitado consumo de produtos e presença nos jogos da seleção.

Os oito fatores gerados pela Análise Fatorial Exploratória explicaram 67,32\% da variância identificada, sendo, em parte, diferentes dos conectores indicados na teoria apresentada por Rein et al. (2008) e utilizada como base da pesquisa. Tal diferença pode ser explicada por problemas na pesquisa e na teoria, como o fato de a mesma ter sido desenvolvida com base em outro contexto, no qual as motivações dos torcedores diferem dos do rugby e da seleção brasileira da modalidade analisados.

Diferenças também foram encontradas na comparação dos resultados com os fatores de motivação e conexão indicados na literatura, revelando características próprias dos torcedores brasileiros de rugby quando comparados com os TCs de outras modalidades esportivas e de outros países. Assim, é reafirmado a importância da realização de estudos que analisem os torcedores/consumidores nacionais, já que eles possuem peculiaridades que limitam a mera reaplicação, por acadêmicos e profissionais, dos resultados de pesquisas realizadas no exterior.

A partir dos resultados podemos indicar algumas sugestões para fomentar o desenvolvimento do rugby no Brasil e da seleção brasileira:

- Ações de comunicação e de relacionamento para manter o engajamento dos torcedores com a seleção durante os períodos sem jogos;

- Desenvolvimento de produtos oficiais, canais de venda e ações para aumentar o consumo dos torcedores; 
- Realização de ações para fidelizar os torcedores e tornar a ida deles aos jogos da seleção mais frequente por meio da criação de experiências únicas e atrativas, com a participação dos patrocinadores da $\mathrm{CBRu}$;

- Desenvolvimento de ações para a criação e manutenção de ídolos e para a aproximação deles dos fãs;

- Ações de comunicação e para atrair as famílias aos jogos, já que elas são um importante influenciador dos torcedores.

Apesar de cumprir seu objetivo a pesquisa apresentou algumas limitações, como possíveis problemas com o questionário, com afirmações/variáveis inadequadas, e o baixo número de respondentes, devido às condições climáticas desfavoráveis e a falta de acesso ao interior do estádio em que a partida foi realizada. Por fim, como sugestões de estudos futuros indicamos a revisão da teoria base a partir dos resultados com a reorganização dos conectores e revalidação da mesma e a aplicação do questionário em outros jogos da seleção com um número maior de respondentes para permitir outras análises e comparações.

Também indicamos analisar a influência do adversário no público dos jogos da seleção brasileira de rugby e a aplicação do questionário em competições e/ou jogos de outras modalidades esportivas para ampliar a adequação dos conectores, iniciais e identificados na pesquisa, a diferentes modalidades e realidades.

\section{Referências}

Agência IBGE. (2018a). PNAD Contínua 2016: 51\% da população com 25 anos ou mais do Brasil possuíam apenas o ensino fundamental completo. Recuperado em 20 set., 2019 de https://bit.ly/2wrxKN3

Agência IBGE. (201b). IBGE divulga o rendimento domiciliar per capita 2017. Recuperado em 20 set., 2019 de_https://bit.ly/2XcWKnM

Alonso, A. D.; O'Shea, M. (2014). Imaging the Game Day Experience: A Case Study of the National Rugby League (NRL). International Journal of Sport Management Recreation \& Tourism, Vol.13, p.38-62.

Andrade, J. L. (2019). O rugby nas aulas de Educação Física do Ensino Médio: desafios e possibilidades. (Dissertação de Mestrado), Universidade Estadual de Maringá, Maringá.

Aranha, F., Zambaldi, F. (2008). Análise Fatorial em Administração. São Paulo: Cenage Leaning.

Brasil Rugby. (2016). Reunião Estratégica Aberta. Recuperado em 20 set., 2019 de https:// tinyurl.com/yauak36e

Brasil Rugby. (2018). Annual Report 2017. Recuperado em 20 set., 2019 de https://tinyurl.com/ y75ujm28

Brasil Rugby. (2019a). Annual Report 2018. Recuperado em 17 abr., 2020 de https:// tinyurl.com/y75ujm28

Brasil Rugby. (2019b). Pelo quinto ano seguido, CBRu é reconhecida pelo Prêmio Sou do Esporte. Brasil Rugby. Recuperado em 17 abr., 2020 de https://tinyurl.com/ycl8gnzr

Brasil Rugby. (s.d.). A CBRu - Sobre nós. Brasil Rugby. Recuperado em 17 abr., 2020 de https://tinyurl.com/y8wwrgxa 
Moraes, I. F., Vanucci, L. H. T., \& Rocco Junior, A. J. (2020). Os fãs da seleção brasileira de Rugby e as suas conexões com a seleção e com a modalidade

Cafeo, M. R. G. (2013). O riso pela fama: análise dos filmes publicitários da Topper e Confederação Brasileira de Rugby. (Dissertação de Mestrado), Faculdade de Arquitetura, Artes e Comunicação da Universidade Estadual Paulista "Júlio de Mesquita Filho", Bauru.

Costello, A. B., Osborne, J. W. (2005). Best practices in Exploratory Factor Analysis: four recommendations for getting the most from your analysis. Pract Assess Res Eval., 10(7), 19.

Dantas, C. R., Perrenoud, L., Marinho, B. L., \& Vanucci, L. H. T. (2017). A relação torcedorseleção brasileira de rugby e suas consequências. Poster apresentado no $8^{\circ}$ Congresso Brasileiro de Gestão do Esporte 2017, Curitiba.

Dhurup, M. (2010). Motivational variables that influence fan attendance in domestic rugby matches: sport management and marketing. African Journal for Physical Health Education, Recreation and dance, 16(2), 204-220.

Farias, A. M. L., \& Laurencel, L. C. (2006). Estatística descritiva. (Apostila), Universidade Federal Fluminense, Rio de Janeiro.

Favero, P. (2018). Rúgbi desafia crise, aumenta receita e vê esporte crescer no Brasil. $O$ Estado de S. Paulo. Recuperado em 20 set., 2019 de https://goo.gl/D1u5af

Freitas, H., Oliveira, M., Saccol, A., \& Moscarola, J. (2000). O método de pesquisa Survey. Revista de Administração, 35(3), 105-112.

Funk, D. C.; James, J. (2001). The Psychological Continuum Model: A Conceptual Framework for Understanding an Individual's Psychological Connection to Sport. Sport Management Review, 4(2), 119-150.

Garland, R.; Macpherson, T.; Haughey, K. (2004). Rugby Fan Attraction Factors. Marketing Bulletin, 15, 1-12.

Gil, A. C. (2002). Como elaborar projetos de pesquisa (Vol. 4. ed.). São Paulo: Atlas.

Gladden, J., \& Funk, D. (2002). Developing an understanding of brand associations in team sport: Empirical evidence from consumers of professional sport. Journal of Sport Management, 16(1), 54-81.

Gutierrez, D. M. (2016). O rugby, identidade e processos econômicos no Brasil. (Dissertação de Mestrado), Escola de Comunicações e Artes da Universidade de São Paulo, São Paulo.

Gutierrez, D. M., Antonio, V. S. R., Kater, T., Almeida, M. A. B. (2017). Um estudo sobre a introdução e institucionalização do rugby no Brasil. J. Phys. Educ., 28(2841).

Hair, J., Black, W., Babin, B., \& Anderson, R. (2014). Multivariate Data Analysis (Vol. 7). Essex: Pearson.

Hora, H. R. M., Monteiro, G. T. R., Arica, J. (2010). Confiabilidade em questionários para qualidade: um estudo com o Coeficiente Alfa de Cronbach. Produto \& Produção, 11(2), 85-109.

Lopes, E. L.; Silva, D. (2011). Modelos integrativos do comportamento do consumidor: uma revisão teórica. REMark - Revista Brasileira de Marketing, 10(3), 3-23.

Malhotra, N. K. (2012). Pesquisa de Marketing: uma orientação aplicada (Vol. 6). Porto Alegre: Bookman.

Melo, J. V. A. (2013). O planejamento estratégico de marketing nas confederações brasileiras de basketball, rugby e vela e motor: estudo de caso múltiplo. (Dissertação de Mestrado Profissional), Faculdade de Economia e Finanças IBMEC, Rio de Janeiro.

Rein, I., Kotler, P., Shields, B. (2008). Marketing Esportivo: a reinvenção do esporte na busca de torcedores. Porto Alegre: Bookman.

Rocco Junior, A. J. (2019). Evolução do Consumidor do Esporte: da distinção social à imersão digital. (Tese de Livre-Docência), Escola de Educação Física e Esporte da Universidade de São Paulo, São Paulo. 
Ross, S. D., James, J. D., Vargas, P. (2006). Development of a Scale to Measure Team Brand Associations in Professional Sport. Journal of Sport Management, 20(2), 260-279.

Rugby World Cup Japan 2019. (2020a). Fun focus sees RWC 2019 social and digital content break new ground and records. Recuperado em 17 abr., 2020 de https://tinyurl.com/y8uvyyqs

Rugby World Cup Japan 2019. (2020b). New research links Japan's Rugby World Cup hosting with national pride and excitement boost. Recuperado em 17 abr., 2020 de https://tinyurl.com/ya4g2skd

Rugby World Cup Japan 2019. (2020c). RWC 2019 sets new broadcast records and inspires new audiences. Recuperado em 17 abr., 2020 de https://tinyurl.com/yddztkbl

Senechal, A. (2018). Público recorde, jogo inédito e Haka: o dia de glória do rúgbi brasileiro. Veja. Recuperado em 20 set., 2019 de https://tinyurl.com/y7pyblcg

Silva, E. L.; Menezes, E. M. (2005). Metodologia da pesquisa e elaboração de dissertação (Vol. 4). Florianópolis: UFSC.

Silva, M. M., Mezzadri, F. M., Souza, D. L., Souza, P. M. (2015). O financiamento público do rugby brasileiro: a relação governo federal e Confederação Brasileira de Rugby. Journal of Physical Education, 26(2), 213-222.

Stewart, B., Smith, A. C. T., Nicholson, M. (2003). Sport Consumer Typologies: a critical review. Sport Marketing Quaterly, 12(4), 206-216.

Tomlinson, M., Buttle, F., Moores, B. (1995). The fan as customer: customer service in sports marketing. Journal of Hospitality and Leisure Marketing, 3(1), 19-33.

Trail, G. T., James, J. D. (2001). The motivation scale for sport consumption: assessment of Scale's Psychometric Properties. Journal of Sport Behavior, 24(1), 108-127.

Veal, A. J., \& Darcy, S. (2014). Research methods in sport studies and sport management: a practical guide. Oxon: Routledge. 